\title{
A SYSTEMATIC REVIEW OF THE APPROACHES ENHANCING THE MATHEMATICS ACHIEVEMENT
}

\author{
SONGÜL TÜMKAYA \\ Faculty of Education, Çukurova University, \\ Balcalı, 01330, Sarıçam, Adana, Turkey \\ E-mail address: songultumkaya01@gmail.com \\ ORCID: http://orcid.org/0000-0003-0140-4640 \\ HAKAN ULUM \\ Institute of Social Science, Çukurova University, \\ Balcalı, 01330, Sarıçam, Adana, Turkey \\ E-mail address: hakanulum@gmail.com \\ ORCID: http://orcid.org/0000-0002-1398-6935
}

\begin{abstract}
Aim. The aim of this study is to analyse the conducted studies in order to reveal the effect of the strategies, methods and techniques used in elementary school mathematics courses, to apply critical strategies based on impartiality, and to critically evaluate and synthesize them.

Methods. In this systematic review study, Preferred Reporting Items for Systematic Reviews and Meta-Analyses (PRISMA) Statement was used in order to prepare the systematic review protocol. The studies were based on students' achievement resulting from student-centred strategy, methods and techniques.

Results. The results of the study show that the number of participants of the primary studies centred on the range of 31- 60 to 90 and above. Moreover, the total number of studies conducted in different countries constitutes a significant proportion of the studies included. In most of the studies $(\mathrm{f}=87)$, significant differences were found in favour of the experimental group.

Conclusion. Within the framework of the inclusion criteria of the research, it can be concluded that student-centred strategy methods and techniques statistically change the students' mathematics achievement. Among these methods and techniques, Realistic Mathematics Education, Computer Assisted Teaching Method, and Collaborative Learning Method were prominent.

Keywords: systematic review, mathematics achievement, primary schools, learning methods
\end{abstract}




\section{INTRODUCTION}

The trends of globalization, information society, and postmodernism have 1 had a significant impact on education in the late $20^{\text {th }}$ and the early $21^{\text {st }}$ centuries. These trends have brought new perspectives and concepts to education. The multichannel flexible education and lifelong education are at their core, and emphasize learning instead of teaching. As a result, the emphasis is put on the learner. The learner is the common denominator of education, while gaining knowledge and skills approaches to ensure persistence (Armstrong, 2000; McCombs \& Whisler, 1997; McTighe \& Wiggins, 1999). Measuring the impact of utilizing these approaches has attracted the attention of researchers.

Primarily improving success rates in mathematics has been in the centre of attention. In order to determine whether the methods used are effective, many experimental studies have been conducted on mathematics education. Upon examining the studies, we have concluded that all of them have had a positive effect on academic achievement in mathematics. A number of studies related to the approaches enhancing mathematics achievement in primary schools were carried out. However, the most effective strategy, methods, and techniques to enhance mathematics success may be attributed to computer-assisted learning, cooperative learning, drama method, educational games, realistic mathematics education, blended learning, learning with music, problem-based learning, project-based learning, scenario-based learning, and multiple intelligence theory (Yesilpinar-Uyar \& Doganay, 2018).

Searching "mathematics," "academic success," and "elementary school" as keywords in Education Resources Information Canter (ERIC) and Social Science Citation Index (SSCI) databases, the number of available studies is 115.271 (as of June 2019). The essential question is whether the teaching strategies, methods, and techniques used in primary schools make a difference in mathematics achievement. We have attempted to select studies for further examination at random. In these studies, we have noticed that student-centred strategies, methods and techniques have a positive effect on mathematics achievement.

Systematic reviews reveal highly consistent approaches to research synthesis. These methods used as a tandem include a scientific approach to the identification, analysis and synthesis of quantitative evidence from previous studies. They can be used to summarize major research, and to create new insights into social work and policy (Littell, Corcoran, \& Pillai, 2008). The results of the research are combined and the general effect of student-centred strategies, methods and techniques used in elementary school mathematics classes are noticeable.

As a result, no quantitative effect size has been obtained due to lack of meta-analysis. However, according to the PRISMA (2009) protocol, a systematic review should be performed without meta-analysis. The importance of the study lays in revealing the whole picture of the current situation in teaching mathematics to primary school children. In this study we will answer the follo- 
wing questions. What strategy methods and techniques (student-centred) have been used in recent years to improve mathematics achievement in primary school students? What is the distribution of important databases? What is the distribution in terms of research type (article/thesis)? In which countries? What are the sample sizes? How do experimental application times change? And, most importantly, is there a statistically significant difference in these studies? If it is statistically significant, it has an effect on academic achievement. Is it necessary to re-study such experimental studies with the same approach (assuming that the independent variables are held constant)? Not all essential differences may have a significant effect. A meta-analysis is needed to demonstrate this effect. As a result of this study, it may reveal the need for meta-analysis.

\section{METHODS}

The authors applied a systematic review method including studies focusing on the same problem and examining all researches in the relevant field. Studies were included in the research according to predominated criteria. Findings were synthesized upon completing the study (Burns \& Grove, 2007; Higgins \& Green, 2011).

In this paper, PRISMA Statement was used in the preparation of the systematic review protocol and writing the article. This method is used to guide future researches and practices by revealing the important links and forms in the literature of educational research (Minner, Levuy \& Century, 2010, cited in Baran \& Bilici, 2015). Certain criteria were used to determine which studies would be systematically reviewed. These studies were based on student achievement resulting from student-centered strategy, methods and techniques. Moreover, they were experimentally designed studies conducted between 2008 and 2018, and scanned by Turkish (TR) Index, ERIC, and Social Sciences Citation Index, ProQuest, and National Thesis Center databases.

\section{DATA COLlECTION PROCEDURE}

A systematic screening approach was adopted in line with the determined criteria. "Elementary school", "success", "experimental", "mathematics" keywords were searched in titles and abstracts. However, depending on the researches database, search engine characteristics, keywords, and search techniques varied. The screening was repeated periodically until the data analysis stage (September 2019). After consulting with experts, the appropriate studies have been selected to be included in the research. Expert opinions were collected through Google Form. In order to ensure experts easy access to the works included in the study, they were uploaded to Google Drive. The experts were asked to review the experimental application in the study through the link included in the form. They were asked to decide whether these practices were a teacher- or student-centered, strategy, method, or technique. The studies were based on 11 forms. With regard to experts' opinions obtained from 11 forms, 


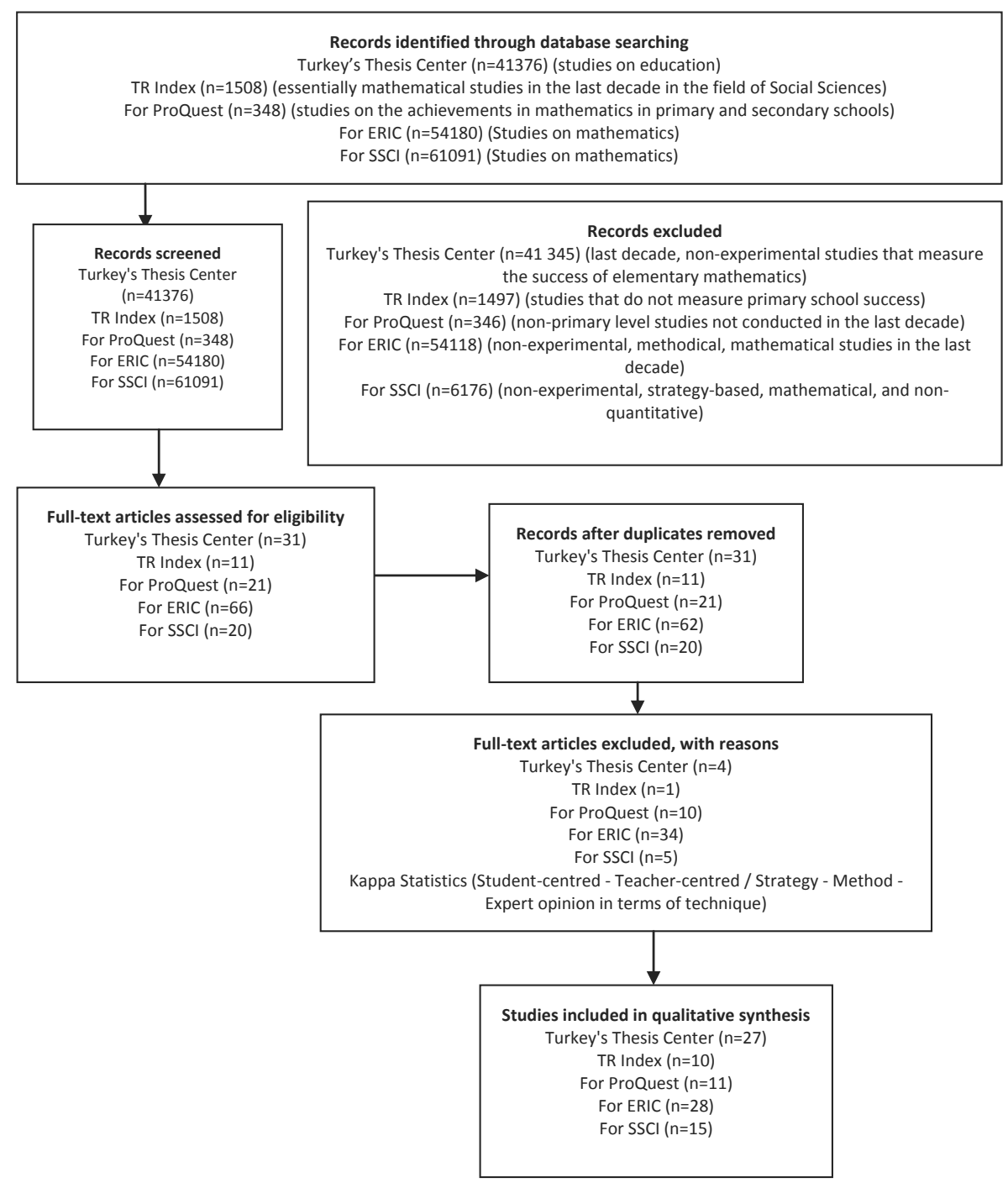

Figure 1.

Flow Diagram from PRISMA (2009).

the authors of the study attempted to obtain opinions of the authorities competent in English as most of the studies on learning-teaching strategy methods and techniques are available in English.

The data with experts' opinions obtained from Google Forms were transferred to Statistical Package for the Social Sciences (SPSS). Following the procedure, Kappa Statistics was applied. The Kappa coefficient measures the agreement between two observers in the evaluation of categorical items which can 
be accidental. Therefore, a stronger than harmony result between the two observers has been noticed. In this study Cohen's kappa coefficient, recommended when considering the concordance between two observers, was used. Thus, by measuring the harmony between the two experts' views, it also took into account that harmony can be an opportunity. The percentage ratio between the two experts' views is considered to be a stronger result than harmony. As a result of all experts' opinion studies, 87 studies obtained systematically were included in the study.

In order to apply in the study, the following figure was adopted from PRISMA (2009). Based on the determined inclusion criteria, the flow diagram contained the phases of Included, Eligibility, Screening, and Identification from the broadest studies to the narrowest ones.

\section{RESULTS}

The results of the study are clarified by the following figures successively. In a similar vein, this systematic review categorizes the related distributions based on the studies in the related literature. As already mentioned, the data presented in the figures were obtained from the studies conducted between 2008 and 2018 by TR Index, ERIC, SSCI, ProQuest and National Thesis Center databases.

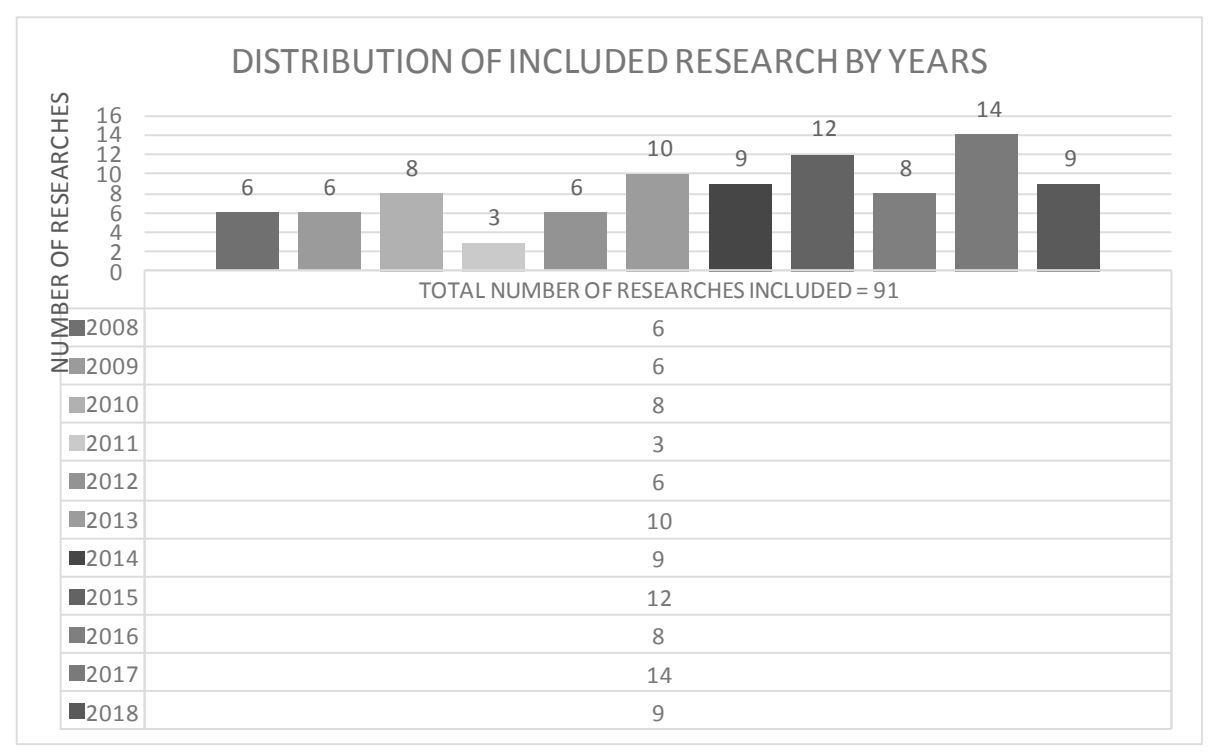

Figure 2.

The distribution of studies by years.

Source: Own research. 
Figure 2 shows the distribution of studies by years. The studies come from the last ten years. Accordingly, most studies were conducted in $2017(n=14)$. This was followed by: $2015(n=12)$ studies. Studies conducted in $2013(n=10)$. Studies conducted in 2018 and $2014(\mathrm{n}=9)$. Studies conducted in 2016 and $2010(\mathrm{n}=8)$. Studies conducted in 2012, 2009 and $2008(n=6)$. Studies conducted in $2011(n=3)$. Therefore, it can be concluded that the frequency of recent studies has increased.

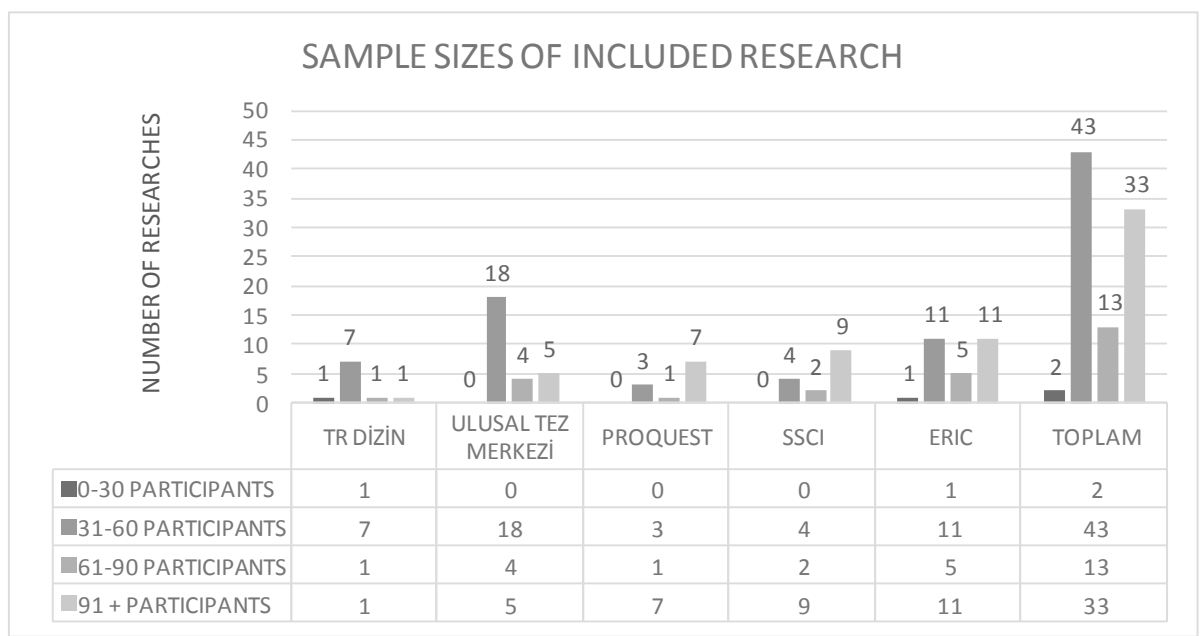

Figure 3.

The sample size of the studies.

Source: Own research.

Figure 3 shows the sample size of the studies. We can see the sample sizes according to the databases. Most of the studies were conducted with 31-60 participants $(n=43)$. This was followed by 91 or more participants $(n=33)$. 61-90 participants $(n=13) .0-30$ participants $(n=2)$. 


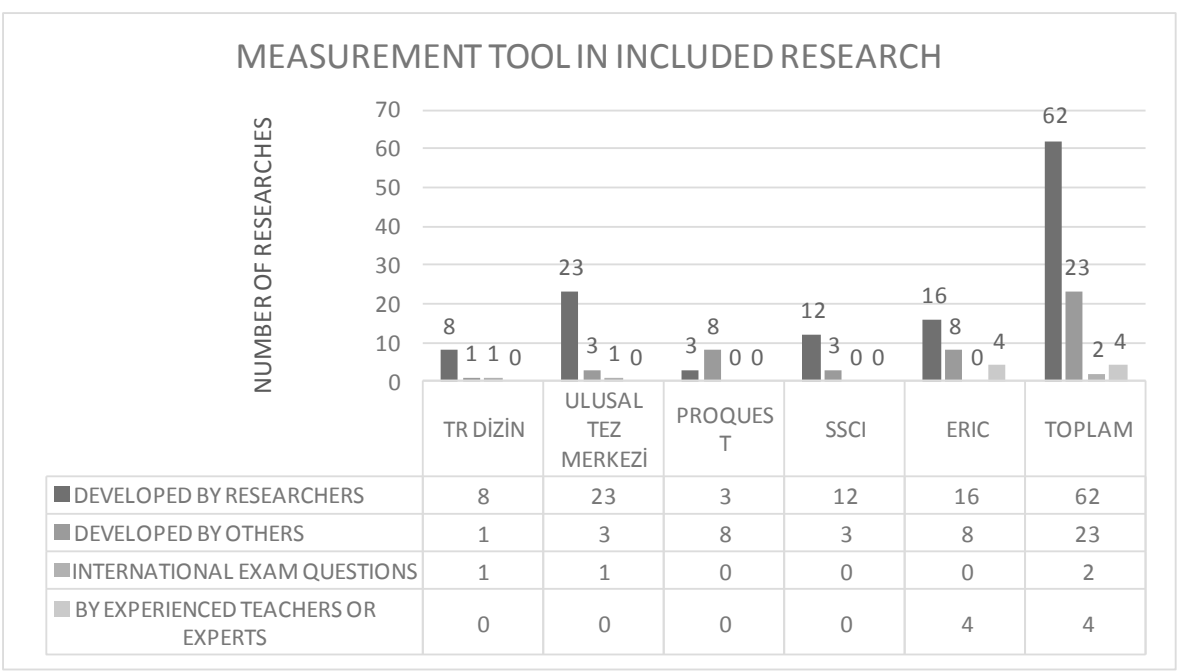

\section{Figure 4.}

The researchers developing the success scales used in the studies.

Source: Own research.

Figure 4 shows who developed the success scales used in the studies. Most of the studies used scales developed by the researchers themselves $(n=62)$. The following were in turn: Ready scales were used $(n=23)$. Scales developed by teachers and experts were used $(n=4)$. International exam questions were used $(n=2)$. Accordingly, the researchers have often preferred to use scales developed by themselves.

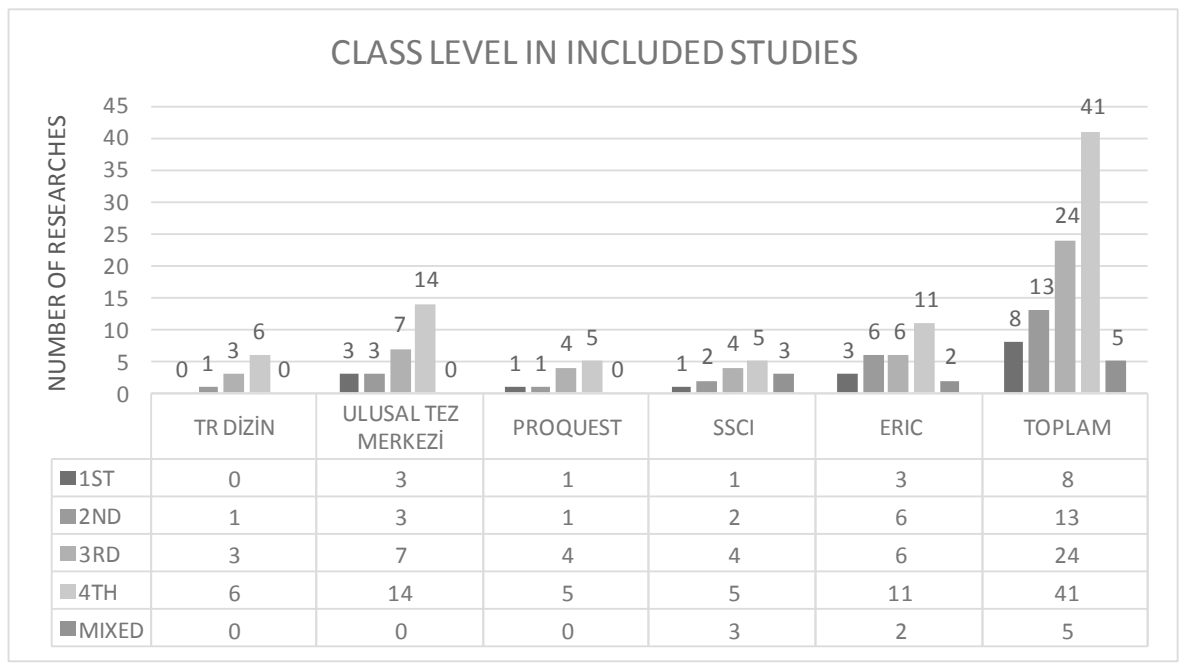

Figure 5.

The class levels.

Source: Own research. 
Figure 5 shows the class levels in which the research was conducted. Most preferred to work with $4^{\text {th }}$-grade students $(n=41)$. The following were respectively: $3^{\text {rd }}$-year students $(n=24), 2^{\text {nd }}$-year students $(n=13)$, and $1^{\text {st }}$-year students $(\mathrm{n}=8)$.

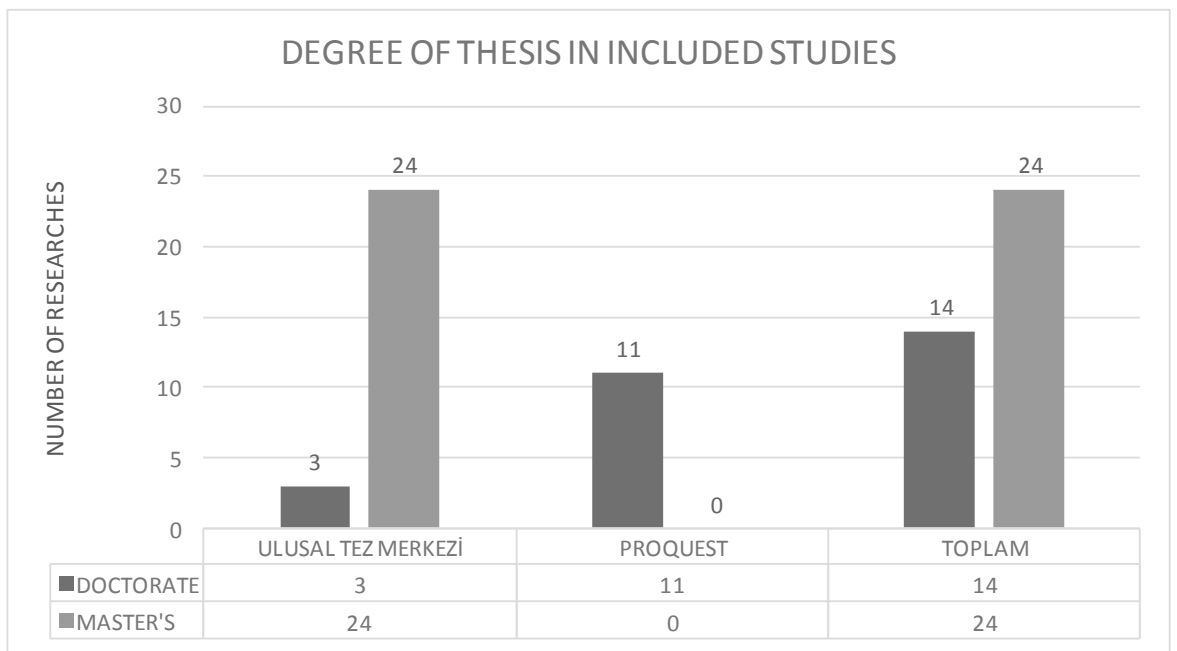

Figure 6.

The degree of theses.

Source: Own research.

Figure 6 shows the number of master $(n=24)$ and doctoral $(n=14)$ theses included in the review. From this point of view, it is concluded that the topic of measuring mathematics achievement in primary schools (in accordance with inclusion criteria) has been the most common in master's theses. 


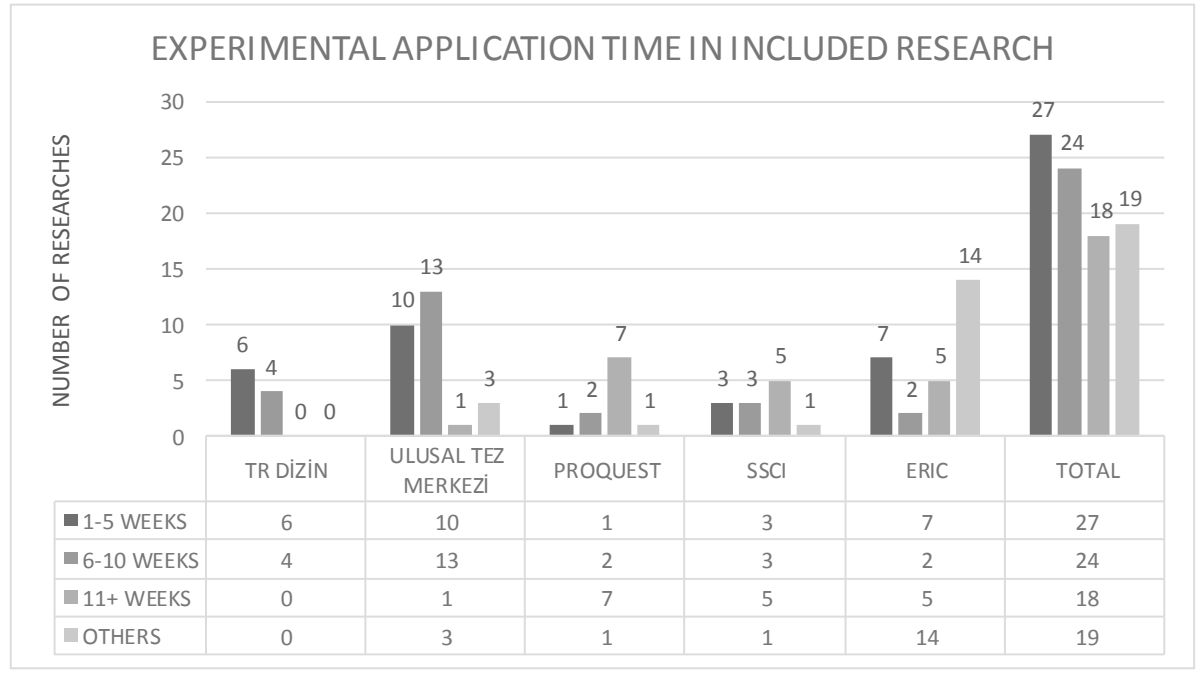

Figure 7.

Duration of experimental studies.

Source: Own research.

Figure 7 shows the duration of experimental studies. It is clearly understood that the duration between 1-5 weeks $(n=27)$ is the initial period followed by the duration between $6-0$ weeks $(n=24)$, 11 weeks or more $(n=18)$, and an uncertain duration $(n=19)$. Moreover, it is easily observed that $1-5$ weeks and 6-10 weeks are highly preferred.

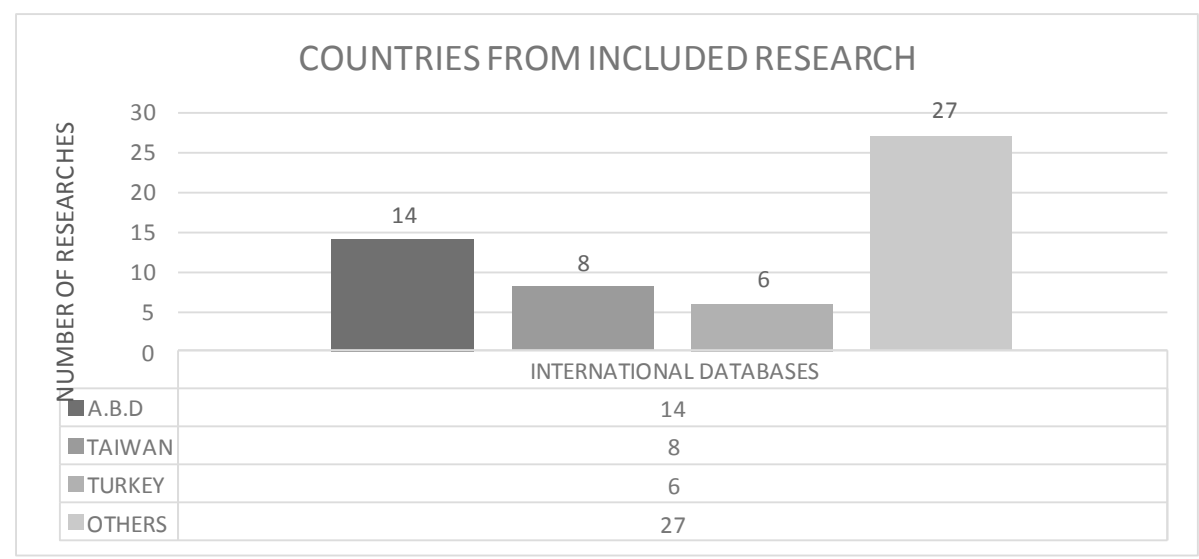

Figure 8.

The countries in which the studies were conducted. Source: Own research. 
Figure 8 shows the countries in which the studies were conducted. Most of the studies were performed in the USA $(n=14)$, followed by Taiwan $(n=8)$ and Turkey $(n=6)$. Besides, the number of studies conducted in other countries cannot be denied $(n=27)$.

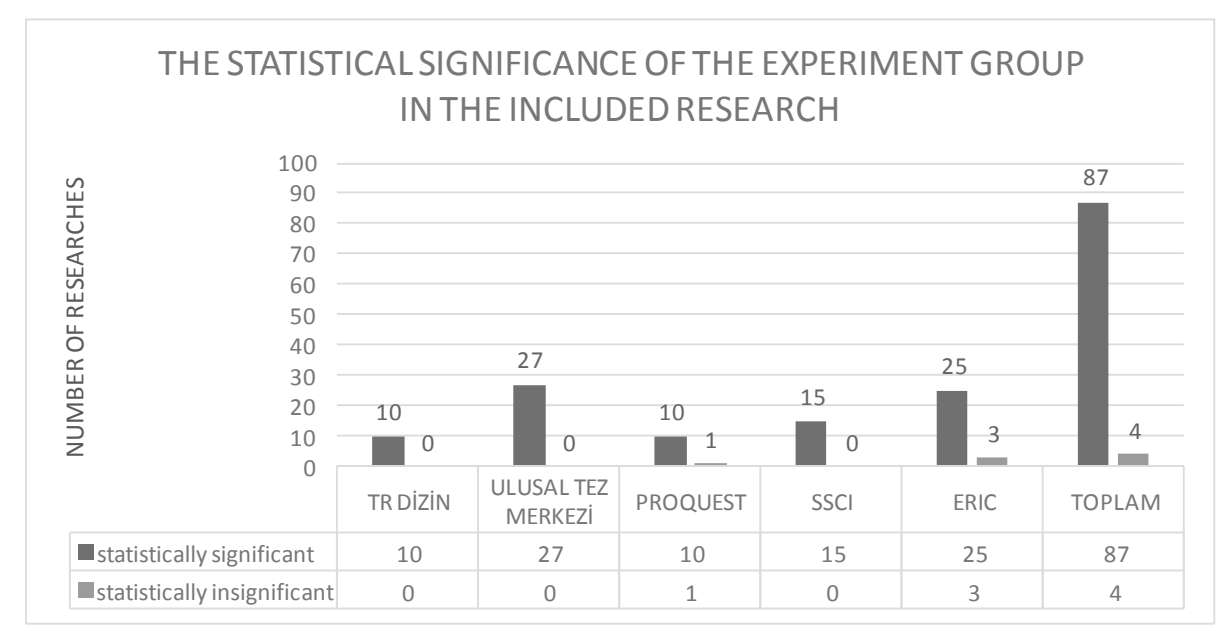

Figure 9.

The statistical results from the studies.

Source: Own research.

Figure 9 shows the statistical results from the studies. A significant difference was found in an essential part of the studies $(n=87)$. The number of studies with no significant difference was quite low $(n=4)$. This result shows that the teaching methods, techniques and strategies used make a difference.

\section{DISCUSSION}

Relevant research has not been found in the context of systematic review. Moreover, in the elementary school mathematics course, no traditional reviews of strategy methods and techniques have been found. The large number of experimental studies on this subject encouraged us to compile. Systematic reviews, which are a kind of literature reviews, aim at a comprehensive and unbiased synthesis of many relevant studies (Aromataris \& Pearson, 2014; Pati \& Lorusso, 2018). Experimental studies were synthesized in a comprehensive and unbiased manner. The results obtained can guide the researchers' experimental studies on this subject, and student-centred strategies, methods and techniques appear to have a positive impact on elementary school teachers' mathematics achievement which makes a statistically significant difference. However, it is necessary to determine the effect level of this difference. The effect size of the strategy, method, and technique used 
will have an impact on practitioners' and researchers' attitude in terms of whether they use it or not.

\section{CONCLUSIONS}

In this meta-analysis study, it was found out that the number of participants of the primary studies centered on the range of 31- 60 to 90 and above. Moreover, the researchers mostly used their self-constructed achievement tests. Furthermore, the grade levels of the participants were the $4^{\text {th }}$ graders, $3^{\text {rd }}$ graders, $2^{\text {nd }}$ graders, and $1^{\text {st }}$ graders respectively. The dissertations in the study are composed of 24 master and $14 \mathrm{PhD}$ theses. Besides, the experimental implementation time of the studies was different but close to each other. The studies were mostly conducted in the USA, Taiwan, and Turkey respectively. Additionally, the total number of studies conducted in different countries constitutes a significant proportion of the studies included. In most of the studies $(f=87)$, significant differences were found in favour of the experimental group.

As a result, within the framework of the inclusion criteria of the research, it can be concluded that student-centred strategy methods and techniques statistically change the students' mathematics achievement. Among these methods and techniques, Realistic Mathematics Education, Computer Assisted Teaching Method, and Collaborative Learning Method were prominent.

\section{LIMITATIONS OF THE STUDY}

This study was limited to certain criteria used to determine which studies would be systematically reviewed. However, these studies were only based on student achievement resulting from student-centred strategy, methods and techniques. Moreover, they were also limited to experimentally designed studies conducted between 2008 and 2018, and scanned by Turkish (TR) Index, ERIC, and Social Sciences Citation Index, ProQuest, and National Thesis Center databases.

\section{REFERENCES}

[1] Armstrong, T. (2000). Information transformation: Teaching strategies for authentic research, projects, and activities. Pembroke Publishers Limited.

[2] Aromataris, E., \& Pearson, A. (2014). The systematic review: an overview. AJN The American Journal of Nursing, 114(3), 53-58. Doi: 10.1097/01.NAJ.0000444496.24228.2c

[3] Baran, E., \& Canbazoğlu Bilici, S. (2015). Teknolojik Pedagojik Alan Bilgisi (TPAB) Üzerine Alanyazın Incelemesi: Türkiye Örneği [A Review of the Research on Technological Pedagogical Content Knowledge: The Case of Turkey]. H. U. Journal of Education, 30 (1), 15-32. Doi: 10.16986/ HUJE.2015013971

[4] Higgins, J. P., \& Green, S. (Eds.). (2011). Cochrane handbook for systematic reviews of interventions (Vol. 4). John Wiley \& Sons.

[5] Littell, J. H., Corcoran, J., \& Pillai, V. (2008). Systematic reviews and meta-analysis. Oxford University Press. 
[6] McTighe, J., \& Wiggins, G. (1999). The Understanding by Design Handbook.

[7] Minner, D. D., Levy, A. J., \& Century, J. (2010). Inquiry-based science instruction-what is it and does it matter? Results from a research synthesis years 1984 to 2002. Journal of Research in Science Teaching, 47(4), 474-496. Doi: 10.1002/tea.20347.

[8] Moher D, Liberati A, Tetzlaff J, Altman DG, The PRISMA Group (2009). Preferred Reporting Items for Systematic Reviews and Meta-Analyses: The PRISMA Statement. PLoS Med 6(7): e1000097. Doi:10.1371/journal.pmed1000097

[9] Pati, D., \& Lorusso, L. N. (2018). How to write a systematic review of the literature. HERD: Health Environments Research \& Design Journal, 11(1), 15-30. Doi: 10.1177/1937586717747384

[10] Uyar, M. Y., \& Doganay, A. (2018). Öğrenci merkezli strateji, yöntem ve tekniklerin akademik başarıya etkisi: bir meta-analiz çalışması [The Effect of Student-Centered Strategies, Methods and Techniques on Academic Achievement: A Meta-Analysis Study]. Mersin Üniversitesi Eğitim Fakültesi Dergisi, 14(1), 186-209. Doi: 10.17860/mersinefd.334542

[11] Vessey, J. A., \& the Founding Oversight Board Members of MASNRN. (2007). Development of the Massachusetts School Nurse Research Network (MASNRN): A practice-based research network to improve the quality of school nursing practice. Journalof SchoolNursing,23(2), 65-72. Doi: 10.1177/10598405070230020201

[12] Whisler, B. L. M. \& Whisler, J. S. (1997). The learner-centered classroom and school. San Francisco: Jossey Bass Publishers. 